Resenha

\title{
(DES)ARQUIVAR: arquivos pessoais e ego-documentos no tempo presente
}

(DES) ARCHIVAR: ARCHIVOS PERSONALES Y EGODOCUMENTOS EN EL TIEMPO PRESENTE.

UN ZIP PERSONAL AND PRIVATE FILES NOWADAYS

(DES) FICHIR LES DOSSIERS PERSONNELS ET LE DOCUMENTS D'EGO DAS LE TEMPS PRESENT

Dóris Bittencourt Almeida*

CUNHA, Maria Teresa Santos. (Des)Arquivar: arquivos pessoais e egodocumentos no Tempo Presente. Florianópolis: Rafael Coppeti Editor, 2019.

"O trabalho com esse material ao longo de minha trajetória e o encantamento pelos seguros indícios de vida ali presentes e nunca abandonados acabaram por fazer de mim uma historiadora dessas coisas ditas ordinárias" (CUNHA, 2019, p. 12). É assim que Maria Teresa Santos Cunha anuncia os propósitos do livro de sua autoria e declara suas afinidades historiográficas.

* Universidade Federal do Rio Grande do Sul (UFRGS), Porto Alegre/RS, Brasil. 
Essas palavras, que estão logo nas primeiras páginas de “(Des)Arquivar", incitam à leitura da obra que reúne produções acadêmicas representativas dos percursos da autora.

Ao apreciar cada capítulo, como não se deixar comover pelas abordagens sensíveis e fecundas desenvolvidas por Maria Teresa? Como não se emocionar ao perceber os frutos de pesquisas de muitos anos em que guardou, garimpou, manuseou, leu e examinou papeis da ordem do comum, outrora desprezados pela historiografia?

Partilhando dos postulados da História do Tempo Presente, o livro está organizado em duas partes. Na primeira, apresentam-se estudos acerca de arquivos pessoais, na sequência, resultados de pesquisas sobre "documentos da intimidade": cartas, diários, álbuns e cadernos. Entre uma e outra parte, somos presenteados com imagens que ilustram as materialidades investigadas: capas de álbuns de recordações, capas de cadernos dos anos 1960, nos quais muitos diários foram escritos, diários pessoais, cartas, cadernos de planejamento, álbum de poesias, cadernos escolares, fotos dos arquivos de Elpídio Barbosa e de Lucas Boiteux.

Metodologicamente, em cada texto, observa-se a intenção da autora em construir reflexões em paralelo à análise dos documentos. Tal estilo de escrita evidencia sua capacidade em operar com as fontes, produzindo uma urdidura entre o referencial epistemológico e a empiria investigada.

Pelo fato dos arquivos pessoais e ego-documentos se constituírem como corpus documental do livro, há problematizações comuns que permeiam as duas grandes seções. Assim, todos os textos se inscrevem na perspectiva da História Cultural da Educação, tendo a ideia de representação como conceito central. Segundo a autora, as memórias de papel, na clave das escritas ditas ordinárias, conservam o reconhecimento de práticas, costumes, rituais e sociabilidades. Ainda, considerando os pressupostos da História do Tempo Presente, Maria Teresa traz a presença de Reinhart Koselleck, sobretudo as questões referentes aos estratos do tempo e ao espaço de experiências, a partir 
da pergunta que ecoa por todas as páginas: "quanto de passado existe no presente?"

Passemos então a examinar com mais evidências o conteúdo de “(Des)Arquivar”. Na primeira parte, quatro artigos tematizam os arquivos pessoais. Maria Teresa chama a atenção para o fortalecimento desse corpus documental. Vale-se dos estudos de Castillo Gomez para buscar aproximações da História da Cultura Escrita, nas interfaces com a História da Educação. Alerta para o fato que, embora produzido individualmente, o arquivo pessoal é uma representação em que está presente o pensamento social que envolve o sujeito em sua temporalidade. Portanto, a escrita, ainda que produzida individualmente, contempla dimensões de uso social.

No artigo inicial, "Essa coisa de guardar... homens de letras e acervos pessoais", a autora conduz o leitor a refletir acerca do dever de memória que nos atinge no tempo presente, que se materializa na intenção preservacionista, em nível pessoal e institucional. Neste texto, é apresentado o acervo da família Boiteux, de Santa Catarina, que conserva memórias individuais e familiares, as quais revelam indícios da escolarização de seus titulares. Está sob a salvaguarda do Instituto Histórico e Geográfico de Santa Catarina, com cerca de 40.000 documentos, sendo mais de 33.000 organizados e catalogados. Tal acervo formado por cartas, atestados, certidões, produções intelectuais, imagens, entre outros documentos, indica, segundo a autora, "práticas de colecionismo relativas à constituição de sujeitos protagonistas de enredos políticos e culturais próprios de uma elite letrada" (CUNHA, 2019, p. 20). A partir do conceito de "homens de letras" (CHARTIER, 1996), identifica os homens da família Boiteux como indivíduos voltados ao estudo, à leitura e a vida em gabinetes. Esses documentos resistiram ao tempo, sobreviveram aos seus proprietários, e a toda sorte de descarte e triagem que poderiam lhes atravessar. Como diz Maria Teresa, “estes acervos guardam o escrito do vivido, guardam a leitura-escritura que os irmãos Boiteux fizeram de si próprios, constituindo-se uma memória que pode ser decodificada por meio da leitura e interpretação de seus documentos" 
(CUNHA, 2019, p.28).

Os próximos textos tratam especificamente das memórias do tempo de estudante de Lucas Alexandre Boiteux, por meio da pesquisa em seus arquivos pessoais. Para tanto, analisam-se oito textos memorialísticos, produzidos por Lucas, intitulados "Bordejos sobre meio século de Marinha", publicados no Jornal do Comércio do Rio de Janeiro, em 1955. Neles, descreve suas memórias acerca do cotidiano escolar, enquanto aluno da Escola Naval. Tais descrições são entendidas como escritas autobiográficas, em que representou, mais de meio século depois, aspectos de sua formação escolar. A investigação permitiu evidenciar as relações entre escrita e memória, por meio das práticas da cultura escolar de seu tempo. Assim, a autora selecionou os registros memorialísticos sobre o cotidiano escolar, notadamente narrativas sobre as disciplinas oferecidas, os professores, seus colegas, a preparação dos enxovais para ingresso na Escola. Além disso, foram analisadas as descrições acerca da arquitetura do prédio da escola, do momento da chegada à Escola, dos trotes aos calouros e das memórias da dieta alimentar a que estavam submetidos os aspirantes de 1897 da Escola Naval. Por meio desses registros, é possível conhecer práticas, saberes e sabores escolares e identificar pelas memórias de um "homem de letras" indícios da educação escolarizada de cunho militar no início da República.

O arquivo pessoal do professor catarinense Elpídio Barbosa é objeto de análise no último dos artigos da primeira parte do livro. Diferente dos anteriores, este arquivo encontra-se sob custódia do Instituto de Documentação e Investigação em Ciências Humanas, um espaço de guarda de documentação e memória científica, pertencente à Universidade Estadual de Santa Catarina. A reflexão sobre esse professor e inspetor escolar que, em determinado período de sua vida, decidiu guardar recortes, fotografias de visitas escolares e registros de comemorações pessoais referentes à sua vida profissional evidencia a relevância de tais papeis, que se constituem em documentos, na estrutura de seu pensamento educacional. De acordo com a pesquisadora, “o fato de guardar, registrar e arquivar a vida permitiu ao historiador do tempo presente acessar 
determinadas temporalidades que podem dizer sobre o próprio presente pela relação entre passado e presente e os usos que esse passado adquiriu na atualidade" (CUNHA, 2019, p. 78). Desse modo, o arquivo pessoal de Elpidio Barbosa nos autoriza a refletir sobre o tempo e pode, enfim, atestar a experiência de um passado que caracteriza e reverbera hoje a experiência do tempo.

E prosseguindo a leitura, chega-se ao segundo momento da obra, em que as cinco publicações centram-se em torno de "documentos de intimidade". São textos que têm em comum fontes extremamente sensíveis, constituídas por cartas, diários, álbuns e cadernos. As duas primeiras debruçam-se exclusivamente em diários íntimos, raros de se localizar, bastante sedutores. Para dialogar com esses documentos, a autora traz para a cena o pensamento de Michel Foucault, referentes à invenção do sujeito moderno. E qual a relação entre diários íntimos e o pensamento foucaultiano? Maria Teresa percebe a escrita dos diários como uma prática também de cunho social em determinado tempo histórico. E quem escreve desenvolveu aprendizados para autogovernarse, de acordo com os pressupostos da sociedade moderna e disciplinar, conforme os enunciados de Foucault. Portanto, essas escritas, por mais que se digam "íntimas", por mais que carreguem subjetividades, contemplam outras dimensões inscritas nos modos como a sociedade se organiza. Nas palavras da autora, os diários "são registros históricos, polifônicos, plurais e acima de tudo constituídos por dispositivos de poder que buscam ressignificar, regular e canalizar os desejos os afetos as sensibilidades" (CUNHA, 2019, p. 123).

Os diários são considerados ego-documentos, escritas de si, até pouco tempo atrás, sem valor para a historiografia, talvez pelas subjetividades que os permeiam. Comumente produzidos sigilosamente, comportam narrativas efêmeras, "significam instantes mínimos, miudezas, aparentemente ordinárias e banais, mas que, ao transmitir exterioridades produziram pelo ato da escrita outros sentidos à ordem do existente" (CUNHA, 2019, p. 120). Entretanto, quando se tornam possibilidades efetivas de pesquisa, "despertam o interesse 
do historiador e podem se fazer ouvir desde que historicizados em uma relação entre a experiência vivida e as representações" (CUNHA, 2019, p. 136). E assim, Maria Teresa indaga ao leitor, "o que buscamos nesses materiais?". E, em seguida, responde: "considerados fontes históricas na clave dos documentos memorialísticos que são produzidos por práticas de escrita autobiográficas, nos fornecem indícios para compreender outros tempos" (CUNHA, 2019, p. 100), por meio da atenção aos sinais do " cultivo e a auscultação do íntimo" (CUNHA, 2019, p. 102), permitem acessarmos e conhecermos experiências pessoais, familiares, profissionais, ou seja, é possível captar um "capital de vivências de uma época, sendo possível neles encontrar fragmentos de laços de sociabilidades de um tempo que foram perenizados pela escrita" (CUNHA, 2019, p. 142)

No primeiro dos estudos sobre diários íntimos, "Do baú ao arquivo: escritas de si, escritas do outro", investigam-se dois conjuntos desses documentos, doados à autora do livro, produzidos entre os anos de 1964 e 1974, por duas mulheres residentes em Florianópolis, identificadas como "L. e V". Trata-se de um material composto por doze cadernos que reúnem escritos dessas mulheres quando tinham entre 14 e 22 anos de idade. Há informações sobre como experienciaram o cotidiano, a vida escolar e o momento político do golpe civil militar de 1964. A autora defende, mais uma vez, a legitimidade desses documentos. Não esquece de dizer que sua produção coincide com a ascensão política e social da burguesia e com o conseqüente desenvolvimento da urbanização. Neste sentido, reflexões de Michelle Perrot enriquecem as análises desenvolvidas.

No segundo texto, "A 'bio' que foi grafada: gênero e modelos geracionais no diário de MRRH”, opera com dois exemplares de diários pertencentes a uma mulher que chegaram às suas mãos pelo correio, também como doação, em 2007. Sugere que essas escritas de si poderiam ser um modo de "mostrar-se ao mundo, uma possibilidade de inventar-se" (CUNHA, 2019, p. 127). Destaca que a leitura desses papeis permite enxergar a cidade de Porto Alegre dos anos 
1960, pois era aonde a escrevente vivia, além de evidenciar aspectos geracionais e de construção de gênero.

O capítulo seguinte, "Uma vida em primeira pessoa: leituras e egodocumentos de uma professora brasileira" reúne escritos ordinários realizados pela "srta M." durante seu curso de professora primária entre 1967 e 1969, em Santa Catarina. São exploradas cadernetas de anotações e diários pessoais, totalizando quatro suportes preservados pela autora. Diferentemente dos demais, neste texto o foco está nas práticas de leitura da "Srta M", por meio da análise dos seus registros das leituras da "Biblioteca das Moças", formada por uma coleção de romances destinados às moças de classe média, muitas delas professoras. Em relação aos diários, são dois cadernos que trazem registros para além do cotidiano, constam informações sobre a vida cotidiana, na clave das experiências vividas por ela referentes à vida escolar como estudante do Curso Normal naquele final dos anos 1960.

Na sequência, um trabalho com escritas epistolares cujo título é "Por hoje é só...”: cartas entre amigas". São investigadas 171 cartas, como conjunto documental, escritas por "Claudia para Lucia”, cujas temáticas giram em torno de assuntos do cotidiano escolar de uma professora primária e aluna do Curso de Pedagogia, portanto, trata-se de um precioso material para o campo da História da Educação, na perspectiva da história da formação docente. Essas epistolas constituem-se em práticas de escrita que dizem muito, tanto de quem fala, como de quem a escreve, ou seja, elas também têm algo a dizer sobre quem a recebe, considerando os afetos que atravessam a troca de correspondências. Assim, observa-se que o estilo confessional e autorreferente costuma se intensificar, ao longo do tempo que dura a correspondência. A autora conclui, afirmando que a análise das epistolas trocadas entre duas mulheres "pode conter engenhosidades em seus assuntos, iluminar hábitos, práticas e valores partilhados e construir representações de época constituindo -se na e pela escrita" (CUNHA, 2019, p. 164).

O último dos capítulos do livro traz outros documentos de intimidade, 
comuns em outras temporalidades, que podem parecer estranhos às novas gerações: são os álbuns de poesias ou de recordações. Foram analisados quatro desses álbuns. Trata-se de uma forma de prestar homenagens escritas para celebrar a amizade entre pares na escola, como "refúgios para o exercício da amizade" (CUNHA, 2019, p. 167). Mesmo sendo lugar de exibição de afetos, constituem-se em preciosidades da cultura escolar, tendo em vista o incentivo da escola a essas práticas de escrita em tempos pretéritos. Portanto, a autora postula a importância desses artefatos para a História da Educação, tendo em vista a quantidade de sinais identificados à cultura escolar, como as marcas das aprendizagens escolares.

Por fim, ainda cabe dizer que o conjunto desses documentos arquivados pela autora, por seus titulares ou por instituições de salvaguarda, aqui neste livro são "(des)arquivados", como o título sugere. São analisados como memórias de determinados sujeitos, homens e mulheres, inscritos em diferentes temporalidades. Em seus guardados, percebem-se evidências dos processos de educação, por isso a obra é tão cara ao campo da História da Educação. O trabalho com papeis ditos ordinários promove outro modo de acesso à cultura escolar de outrora, difícil de localizar em outras fontes, justamente pelas sensibilidades que comportam. De acordo com Maria Teresa, "documentos dessa espécie apontam para outras estratégias de visibilidade de uma época e permitem observar que enquanto os arquivos públicos calam, os documentos privados, agora tornados públicos, podem fornecer informações e indícios sobre o cotidiano e sobre as formas de ver o mundo a partir de fatos comuns da experiência humana" (CUNHA, 2019, p. 142).

\section{REFERÊNCIAS}

CHARTIER, Roger, L'homme de lettres. In: VOVELLE, Michelle. (Org.) L'homme de lumières. Paris. Edittions de Seuil, 1996. 
DÓRIS BITTENCOURT ALMEIDA é professora de História da Educação da Faculdade de Educação e do Programa de Pós-graduação em Educação da Universidade Federal do Rio Grande do Sul (UFRGS).

E-mail: almeida.doris@gmail.com

(1) http://orcid.org/0000-0002-4817-0717

Recebido em: 11 de novembro de 2019

Aprovado em: 20 de abril de 2020

Editora responsável: Terciane Luchese

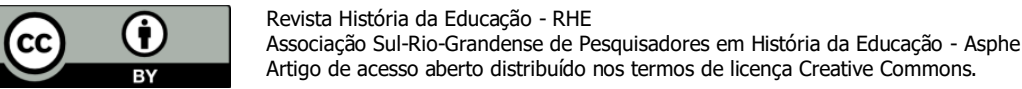

